\title{
IDH1R132H-Specific Peptide Vaccine PEPIDH1M
}

National Cancer Institute

\section{Source}

National Cancer Institute. IDH1R132H-Specific Peptide Vaccine PEPIDH1M. NCI

Thesaurus. Code C117235.

A peptide vaccine consisting of a peptide derived from isocitrate dehydrogenase 1 (IDH1) containing the point mutation R132H (IDH1R132H), with potential antineoplastic activity. Intradermal vaccination with the IDH1R132H-specific peptide vaccine PEPIDH1M may stimulate the host immune system to mount a cytotoxic $T$ lymphocyte $(C T L)$ response against tumor cells that express the IDH1R132H protein. The IDH1 point mutation of amino acid residue 132 is highly expressed in gliomas and is associated with increased production of the oncometabolite R-2-hydroxyg lutarate (2HG). 